\title{
PREVALENCE OF TEMPOROMANDIBULAR JOINT DISORDERS EVALUATION OF VARIOUS SIGNS AND SYMPTOMS AND POSSIBLE CONTRIBUTING AETIOLOGICAL FACTORS
}

\author{
Mohsin Muzaffar Tak'1, Altaf Hussain Chalkoo²
}

${ }_{1}^{1}$ Associate Professor, Department of Oral Medicine and Radiology, Government Dental College, Srinagar, Jammu and Kashmir, India. ${ }^{2}$ Professor and HOD, Department of Oral Medicine and Radiology, Government Dental College, Srinagar, Jammu and Kashmir, India.

\section{ABSTRACT}

\section{BACKGROUND}

The Temporomandibular Joint Disorders (TMDs) comprise a constellation of symptoms affecting the joint and the muscles involved in jaw movement. The aetiology of TMD is little understood, but has been attributed to several factors including trauma, emotional stress, malocclusion and parafunctional habits (Clenching or Bruxing). Patients present with varied signs and symptoms like complaining of pain in the orofacial region, limited jaw opening, clicking and popping sound. The present article is an epidemiological study of the prevalence of signs and symptoms of the Temporomandibular Joint Disorder (TMJ).

The aim of the present study was to determine the prevalence of signs and symptoms of temporomandibular joint disorder.

\section{MATERIALS AND METHODS}

A total of 500 patients were evaluated for Temporomandibular disorders, out of which 127 patients comprising of 82 females and 45 males aged between 20 - 65 years showed features in concurrence with temporomandibular joint disorders. A detailed evaluation of TMJ and associated muscles was carried out.

\section{RESULTS}

The results showed the prevalence of $25.4 \%$ with a female predilection. Clicking was the most prominent among the objective signs and symptoms.

\section{CONCLUSION}

The results obtained indicate that quite a high number of patients may be suffering from temporomandibular joint disorders in the given populace. Moreover, disturbance in the occlusion due to missing teeth and duration of edentulous period may have contributory role in progression of temporomandibular disorders apart from other aetiological factors. Keeping in view the results obtained from the present study, it is needed that a study with a larger sample size may be taken up, so as to identify the populace suffering from TMJ disorders and accordingly treating them at the earliest.

\section{KEY WORDS}

Temporomandibular Disorders, Edentulous, Clicking, TMJ Pain, Myofascial Pain.

HOW TO CITE THIS ARTICLE: Tak MM, Chalkoo AH. Prevalence of temporomandibular joint disorders evaluation of various signs and symptoms and possible contributing aetiological factors. J. Evolution Med. Dent. Sci. 2018;7(38):4148-4151, DOI: $10.14260 /$ jemds/2018/928

\section{BACKGROUND}

The Temporomandibular Joint (TMJ) is composed of the joint cavity, the mandibular condyle, articular disc, muscles and nerves which interact with various structures such as the cervical spine and orofacial region. When the physiological patterns of some of these components are altered, functional and structural disorders can be generated resulting in a clinical impact.1,2 The aetiology of TMD has spawned countless controversies and multiple hypotheses attempting to explain its occurrence. ${ }^{3,4}$ However, it is accepted that TMD has a multifactorial aetiology involving a strong biopsychosocial component and other components of nonspecific nature. 5,6

'Financial or Other Competing Interest': None.

Submission 04-08-2018, Peer Review 01-09-2018,

Acceptance 06-09-2018, Published 17-09-2018.

Corresponding Author:

Dr. Mohsin Muzaffar Tak,

Habak Zakura Crossing,

Hazratbal, Srinagar-190006,

Jammu and Kashmir,

India.

E-mail:mohsintak@yahoo.com

DOI: $10.14260 /$ jemds $/ 2018 / 928$

\section{MATERIALS AND METHODS}

The present cross-sectional study was conducted on 500 (312 females and 188 males) subjects visiting the Department of Oral Medicine and Radiology, Government Dental College, Srinagar. Out of these subjects, 127 patients had features consistent with temporomandibular disorders and hence were included in the present study. These 127 patients comprised of 82 females and 45 males aged between 20 - 65 years.

\section{Clinical Examination}

The Clinical Investigation was carried out with the help of a Mouth Mirror, a Metal Ruler and a Stethoscope-

- Clicking or crepitation was assessed by auscultation with a stethoscope.

- Masticatory muscles were examined by digital palpation.

- The maximum jaw opening was measured using a millimetre scale, less than $40 \mathrm{~mm}$ was regarded as reduced opening capacity. ${ }^{7}$

- Deviation along the opening path of mandible was stated if it was $2 \mathrm{~mm}$ or more horizontally. ${ }^{8}$

- The patient examined intraorally to discover whether the missing tooth or teeth is in anterior or posterior region, and whether the posterior missing teeth/ tooth is unilateral or bilateral. ${ }^{9}$ 


\section{Inclusion Criteria}

Patients with no previous history of trauma or muscle disorder and showing the following symptoms on examination were included in the study-

- TMJ pain.

- Clicking sound.

- $\quad$ Reduced mouth opening.

- Masticatory muscle pain.

- Deviation with mouth opening.

\section{Exclusion Criteria}

Patients who were completely edentulous or with complete dentures were excluded from the study.

\section{RESULTS}

The prevalence of temporomandibular joint disorders in the present study is $25.4 \%$ (Table 1 ). The presence of various signs and symptoms was slightly greater in the female population $(64.6 \%)$ as compared to the male patients, which was (35.4\%) (Table 2) (Fig. 1). Clicking was the most common among various signs and symptoms followed by pain in the temporomandibular joint and reduction in mouth opening was the least (Table 3), (Figure 2).

It was observed that out of 127 patients selected for the study, 94 patients were partially edentulous and the edentulous period varied from less than 3 years to more than 3 years for some of the patients (Table 4). It was also observed that with the increase in duration of edentulous period, there was an increase in the number of symptomatic patients (Table 5) (Diagram 4).

\begin{tabular}{|c|}
\hline Total No. of patients screened for the study $=500$ \\
\hline Total No. of symptomatic patients with signs of TMJ $=127$ \\
\hline Prevalence $=25.4 \%$ \\
\hline Table 1 \\
\hline
\end{tabular}

\begin{tabular}{|c|c|c|}
\hline Gender & Frequency & Percentage \\
\hline Male & 45 & 35.4 \\
\hline Female & 82 & 64.6 \\
\hline Total & $\mathbf{1 2 7}$ & $\mathbf{1 0 0}$ \\
\hline Table 2. Gender distribution of Symptomatic Patients \\
\hline
\end{tabular}

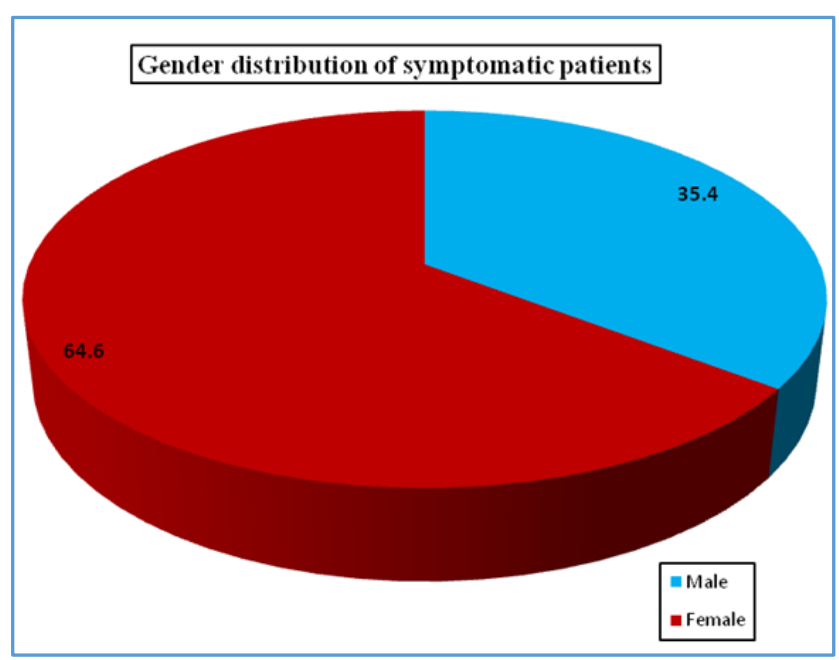

Figure 1

\begin{tabular}{|c|c|c|}
\hline Disorder & Male & Female \\
\hline Clicking & 27 & 39 \\
\hline TMJ pain & 25 & 31 \\
\hline Reduced mouth opening & 11 & 10 \\
\hline Masticatory muscle pain & 20 & 24 \\
\hline Deviation with mouth opening & 13 & 16 \\
\hline Table 3. Distribution of Objective Signs and Symptoms \\
according to Gender that are having One or More \\
Disorders \\
\hline
\end{tabular}

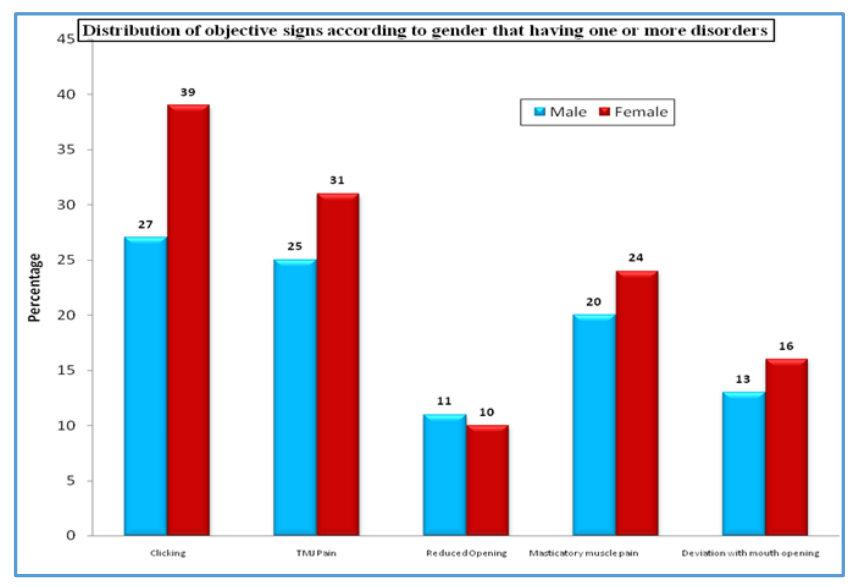

Figure 2

\begin{tabular}{|c|c|c|}
\hline $\begin{array}{c}\text { Partially } \\
\text { Edentulous Span }\end{array}$ & Male & Female \\
\hline$<3$ Years & 9 & 20 \\
\hline$>3$ Years & 23 & 42 \\
\hline Table 4. Various TMD Signs and Symptoms in relation to \\
partially Edentulous Span \\
\hline
\end{tabular}

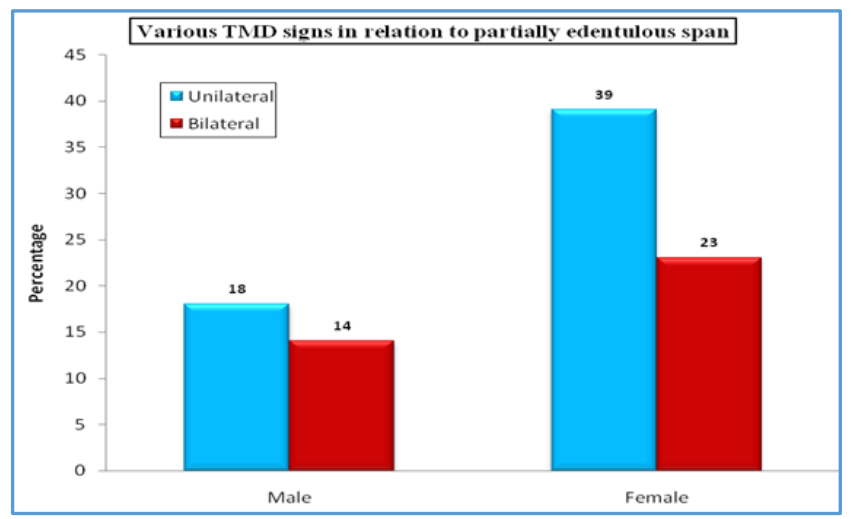

Figure 3

\begin{tabular}{|c|c|c|}
\hline Partial Edentulous Type & Male & Female \\
\hline Unilateral & 18 & 39 \\
\hline Bilateral & 14 & 23 \\
\hline Table 5. Various TMD Signs and Symptoms in relation to \\
partially Edentulous Type \\
\hline
\end{tabular}




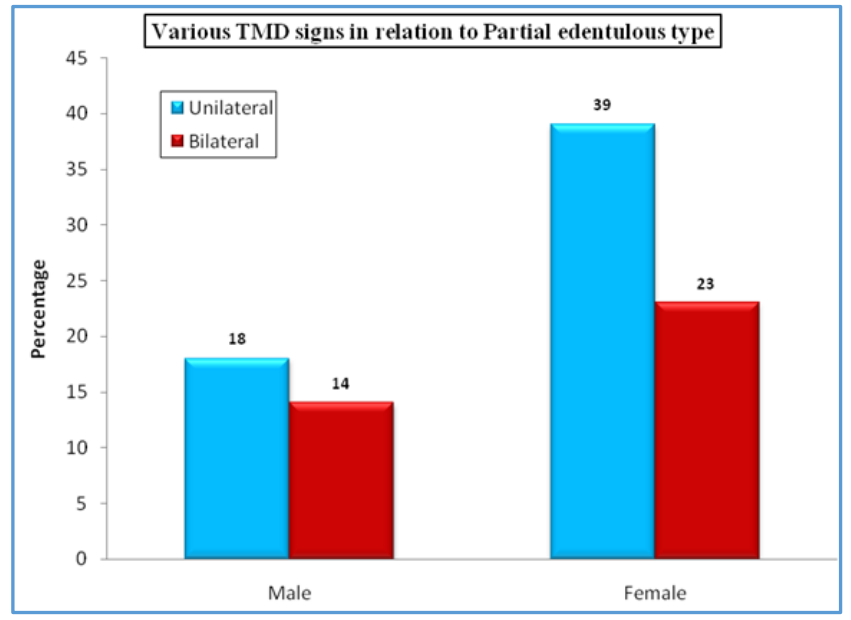

Figure 4

\section{DISCUSSION}

In the present study a total 500 individual (patients) were examined, comprising of 312 female and 188 male patients. About 127 patients comprising of (Male- 45, Female- 82) were found symptomatic and presented with various signs and symptoms of TMD.

As has been widely reported in the literature that the frequency of TMJ dysfunction, signs and symptoms is more in female population than in male population. The results obtained in the present study are in concurrence with the findings in literature. ${ }^{10,11}$ This has been interpreted as a reflection of biological, psychological and hormonal differences between two groups. ${ }^{12}$

Patients presented with a wide-spectrum of signs and symptoms in the present study. The most common sign presented in this study was TMJ clicking, which is in accordance to the studies conducted in the past. ${ }^{13}$ However, TMJ pain which was the second most common sign is in disagreement with the study carried out by. ${ }^{14}$

Occlusal imbalance may be one of the key factors, which may precipitate or may act as a precursor for TMJ disorders. Present study also revealed that occlusal imbalance caused due to missing teeth resulting in partial edentulism (unilateral or bilateral) in patients showed various signs and symptoms of TMD. As been documented in the literature that patients with few remaining natural teeth may have a higher incidence of TMJ dysfunction signs. ${ }^{15}$ However, certain studies also point out that there is no sufficient evidence of association between TMJ dysfunction and partially edentulism. ${ }^{16}$

Further, it was observed in the present study that duration of edentulism lead to increase in severity of signs and symptoms as has been highlighted in other related studies as well.11,16,13

\section{CONCLUSION}

The prevalence of Temporomandibular joint disorders was found to be $25.4 \%$ in the present study, which is quite significant. It indicates that quite a high number of patients may be suffering from temporomandibular joint disorders in the given populace. Also, the presentation of signs and symptoms is quite diverse. Moreover, it has been observed that disturbance in the occlusion due to missing teeth which may be unilateral or bilateral and duration of edentulous period may have contributory role in progression of temporomandibular disorders apart from other aetiological factors. Keeping in view the results obtained from the present study, a study with a larger sample size may be taken up so as to identify the populace suffering from TMJ disorders and accordingly treat them at the earliest.

\section{REFERENCES}

[1] Manfredini D, Guarda-Nardini L, Winocur E, et al. Research diagnostic criteria for temporomandibular disorders: a systematic review of axis I epidemiologic findings. Oral Surg Oral Med Oral Pathol Oral Radiol Endod 2011;112(4):453-62.

[2] Yekkalam N, Wänman A. Prevalence of signs and symptoms indicative of temporomandibular disorders and headaches in 35-, 50-, 65- and 75-year-olds living in Västerbotten, Sweden. Acta Odontol Scand 2014;72(6):458-65.

[3] Yu Q, Liu Y, Chen X, et al. Prevalence and associated factors for temporomandibular disorders in Chinese civilian pilots. Int Arch Occup Environ Health 2015;88(7):905-11.

[4] Miranda S, Gayoso C, Ruiz P, et al. Prevalence of neuropathic symptoms in patients referred for temporomandibular disorder in a Chilean hospital, 2014-2015. J Oral Res 2015;4(4):263-9.

[5] Kim YK, Kim SG, Im JH, et al. Clinical survey of the patients with temporomandibular joint disorders, using Research Diagnostic Criteria (Axis II) for TMD: preliminary study. J Craniomaxillofac Surg 2012;40(4):366-72.

[6] Slade GD. Epidemiology of temporomandibular joint disorders and related painful conditions. Mol Pain 2014;10(Suppl 1):016.

[7] Okasan JP. Fundamental of occlusion and tempromandibular disorders. St, Louis: CV Mosby Co., 1985: p. 185.

[8] Helkimo M. Studies on function and dysfunction of the masticatory system. II. Index for anamnestic and clinical dysfunction and occlusal state. Sven Dent J 1974;67(2):101-21.

[9] Garcia AR, Gallo AK, Zuim PR, et al. Evaluation of temporomandibular joint noise in partially edentulous patients. Acta Odontol Latinoam 2008;21(1):21-7.

[10] Hiltunen K, Peltola JS, Vehkalahti MM, et al. 5-year follow-up of signs and symptoms of TMD and radiographic findings in the elderly. Int J Prosthodont 2003;16(6):631-4.

[11] Shet RGK, Rao S, Patel R, et al. Prevalence of temporomandibular joint dysfunction and its signs among the partially edentulous patients in a village of North Gujarat. J Contemp Dent Pract 2013;14(6):1151-5.

[12] Dao TT, LeResche L. Gender differences in pain. J Orofac Pain 2000;14(3):169-84.

[13] Costen JB. Syndrome of ear and sinus symptoms dependent upon disturbed function of the temporomandibular joint. Ann Otol Rhinol Laryngol 1934;43:1-15.

[14] Carlsson GE. Epidemiology and treatment need for temporomandibular disorders. J Orofac Pain 1999;13(4):232-7. 
[15] Agerberg G, Carlsson GE. Functional disorders of the masticatory system. I. Distribution of symptoms according to age and gender as judged from investigation by questionnaire. Acta Odontal Scand 1972;30(6):597-613.
[16] Pullinger AG, Seligman DA, Gornbein JA. A multiple logistic regression analysis of the risk and relative odds of temporomandibular disorders as a function of common occlusal features. J Dent Res 1993;72(6):96879. 